\title{
Development of a screening procedure for the characterization of Botryococcus braunii strains for biofuel application
}

\author{
Benjamin Moutel ${ }^{\mathrm{a}}$, Olivier Gonçalves ${ }^{\mathrm{a}, *}$, Fabienne Le Grand ${ }^{\mathrm{b}}$, Marc Long ${ }^{\mathrm{b}}$, \\ Philippe Soudant ${ }^{\mathrm{b}}$, Jack Legrand ${ }^{\mathrm{a}}$, Dominique Grizeau ${ }^{\mathrm{a}}$, Jérémy Pruvost ${ }^{\mathrm{a}}$ \\ a LUNAM Université, Université de Nantes, CNRS, GEPEA, UMR 6144, Bât. CRTT, 37 bd de l'Université, BP 406, F-44602 Saint-Nazaire Cedex, France \\ b Plateforme d'analyse des lipides marins LIPIDOCEAN; Laboratoire des sciences de l'Environnement MARin (LEMAR-UMR 6539), Institut Universitaire \\ Européen de la Mer, Technopôle Brest-Iroise, rue Dumont d'Urville, 29280 Plouzané, France
}

\begin{abstract}
A B S T R A C T
An integrated screening approach was developed to assess the potential of the Botryococcus genus for the production of lipids for biofuel application (hydrocarbons and triacylglycerols). The strategy developed in this study permitted to rigorously measure mandatory parameters for the determination of strain performance - i.e. growth rate and oil content. For that purpose, mini-photobioreactors run in parallel were used together with an exhaustive lipid class analysis. The quantitative productivity measurements indicated that the ten screened strains presented very different patterns in the conditions of PBR culture, firstly run in batch, and secondly in continuous mode. Indeed, with the applied setup, only four strains presented biomass productivities close to that previously measured for the reference strain $807 / 1$ (between 74 and $307 \mathrm{mg} \mathrm{L}^{-1}$ day $^{-1}$ of biomass for the tested strains). HC productivity obtained under continuous light ( $\sim 14 \mathrm{mg} \mathrm{L}^{-1}$ day $\left.^{-1}\right)$ was close to that measured for the strain $807 / 1\left(\sim 20 \mathrm{mg} \mathrm{L}^{-1} \mathrm{day}^{-1}\right)$, confirming $B$. braunii tested strains potential for biofuel application. The analysis of the lipid chemodiversity revealed moreover that this genus should be further investigated for its polar lipids, as it suggests potential pharmaceutical applications such as production of antitumorals or immunosuppressors.
\end{abstract}

\section{Introduction}

Microalgae are the most studied bioresources in the search for sustainable biofuel production [1]. Within the remarkable diversity of microalgae, Botryococcus braunii holds a very unique place and has been studied specifically as a new source for jet fuel since the 1980s [2]. It produces very large amounts of polyaldehydic or polyetheric compounds (polymers that mainly constitute the outer

Abbreviations: CL, cardiolipin; DGDG, digalactosyldiacylglycerol; DIC, dissolved inorganic carbon; DW, dry weight; EOSS-PBR, efficient overproducing strain screening photobioreactor; FA, fatty acid; GC-FID, gas chromatography coupled to a flame ionization detector; HC, hydrocarbon; HPTLC, high-performance thin layer chromatography; LPC, lysophosphatidylcholine; MTCS, medium highthroughput cultivation screening; MGDG, monogalactosyldiacylglycerol; NL, neutral lipids; OD, optical density; ONL, other neutral lipids; PBR, photobioreactor; PC, phosphatidylcholine; PE, phosphatidylethanolamine; PFD, photon flux density; PG, phosphatidylglycerol; PI, phosphatidylinositol; PL, polar lipid; PS, phosphatidylserine; RSD, relative standard deviation; SM, sphingomyelin; SQDG, sulfoquinovosyldiacylglycerol; TAG, triacylglycerol; TL, total lipids.

* Corresponding author.

E-mail address: olivier.goncalves@univ-nantes.fr (O. Gonçalves).

$\begin{array}{ll}\text { Symbols } & \\ C_{\mathrm{x}} & \text { Biomass DW concentration } \\ \mathrm{P}_{\mathrm{HC}} & \text { Hydrocarbon productivity } \\ \mathrm{P}_{\mathrm{TAG}} & \text { Triacylglycerol productivity } \\ \mathrm{P}_{\mathrm{x}} & \text { Biomass DW productivity } \\ \mathrm{t}_{\mathrm{d}} & \text { Doubling time } \\ \mu_{\max } & \text { Maximum specific growth rate }\end{array}$

cell wall of the microalgae) and hydrocarbons (HC), constituting up to $10 \%$ and $60 \%$ of their dry weight (DW) respectively [3]. The main industrial potential of $B$. braunii relies on its ability to directly produce $\mathrm{HC}$ by photosynthesis. These lipids fit jet fuel specificities, as they do not contain oxygen and are formed of long-chain alkenes (with terminal double bonds, of major interest to the olefin chemists) or botryococcenes (with original methyl squalene-like compounds). HC accumulate in large quantities within the original structural organization of $B$. braunii biomass and are thus easily convertible in jet fuels in contrast to more usual lipids such as 


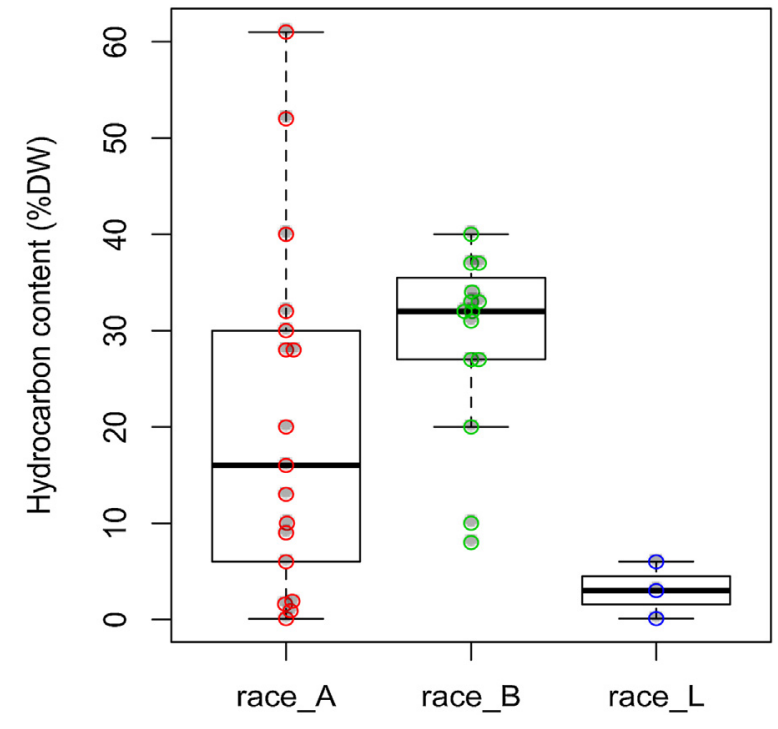

Fig. 1. Variability of the hydrocarbon content of Botryococcus braunii. Data from 35 measurements obtained for different strains of the three races of $B$. braunii, A, $\mathrm{B}$, and $\mathrm{L}$, and different culture conditions were used for the graphical summary $[2,5,6,7,61-64]$. Data are expressed as dry weight percentage (DW\%).

triacylglycerols (TAG) which require further expensive chemical modifications.

Strains of $B$. braunii were classified in three different races (A, B and L) according to the type of HC they synthesize. Race A strains produce $n$-alkadienes and $n$-alkatrienes $\left(C_{25}-C_{31}\right)$. Race $B$ strains produce polymethylated unsaturated triterpenes called botryococcenes $\left(\mathrm{C}_{n} \mathrm{H}_{2 n-10}, n=30-37\right)$. Race L strains produce a single tetraterpene, named lycopadiene $\left(\mathrm{C}_{40} \mathrm{H}_{78}\right)$ [4]. HC content of Botryococcus species was generally found high but was also extremely variable depending upon culture conditions, species and strains. HC content can vary from 2.6 [5] to c.a. $60 \%$ DW [6]. Fig. 1 summarizes the data extracted from 35 published measurements of $\mathrm{HC}$ content in strains of the three known races. It also clearly indicates the potential to produce $\mathrm{HC}$ for the strains of the races A and B with a median of respectively $16 \%$ DW and 33\% DW. Race L strains were clearly less productive for HC, with a median HC content of 3\%DW for an extracted oil composed of a single tetraterpene (lycopadiene) [7]. Other important features of $B$. braunii are its low growth rate, with a minimum generation time of 2 days [4] and its specific colonial organization in which cells are embedded in a mucilaginous sheath. This low growth rate, combined to the risk of rapid cellular degeneration of $B$. braunii, results in a strong instability if the culture conditions are not controlled $[6,8]$.

$B$. braunii is thus a complex biological model, with high variability of physiological behaviors [9] that needs to be taken into account for the optimization of its cultivation [10]. Growing conditions could be optimized for $B$. braunii, as already done for other microalgae models, using medium- and high-throughput cultivation screening approach (MTCS) through response surface methodology [11-13]. Nevertheless, it still makes strains characterization laborious, particularly for the study of their biofuel potential. To answer such a challenge, cultivations in rigorously controlled conditions need to be also performed. The culture in photobioreactors (PBR) instead of microplates or flasks should allow to more reliably monitor and control parameters that greatly influence the photosynthetic metabolism of the microalgae (incident photon fluxes, carbon supply, $\mathrm{pH}$, temperature, etc.), generating therefore experimental conditions suitable for scale-up perspectives $[14,15]$. However, in such a process context, a MTCS approach could not reasonably be performed simultaneously, since it will add too much variables to be taken into account for PBR conditions optimization.

In the majority of the studies on $B$. braunii cultivated in PBR [6,10,14,16-21], airlift PBR with tubular geometry were used in batch mode with fixed cultivation conditions. It led to reach up to $30 \%$ of $\mathrm{HC}$ in DW and biomass concentration up to $6 \mathrm{~g} \mathrm{~L}^{-1}$. The use of the batch mode was mainly justified by the fact that $B$. braunii $\mathrm{HC}$ biosynthesis was related to its photosynthetic growth. When compared to the methodologies usually employed for the cultivation of the TAG-accumulating strains, for which nitrogen starvation is needed to induce lipid accumulation [22], it highlighted another interest of exploiting HC from B. braunii i.e. the simplicity of their production mode. Even though batch culture could still be used, since $\mathrm{HC}$ and biomass productions were simultaneous, continuous culture appeared to be also a suitable cultivation mode for $B$. braunii. Continuous culture in the general case of microalgae, gives also another particular benefit by reducing the light attenuation which progressively increases in batch culture with the biomass density augmentation. Moreover, the physiological responses associated to the photosynthetic process could evolve with the batch culture age, biasing therefore the analysis of results. In continuous mode, light attenuation is constant since the cell population is maintained at a fixed concentration [23]. The microalga metabolism is therefore maintained in a stationary state, permitting the robust measurement of parameters such as productivities for well-defined conditions of light absorption in the culture volume. Moreover long-term experiment can be conducted, permitting the strain to fully adapt to the culture conditions, here in the case of PBR culture [24]. However, in the latest studies involving well controlled cultivation experiments of $B$. braunii, comparison was especially difficult since the experiments were conducted in various conditions (batch, continuous, immobilized, etc.) and time scale [18,25-31]. Such heterogeneity of the experimental production conditions constitutes a real bottleneck that needs to be overcome for an unbiased (as possible as it could be) measurement of the strain process performance parameters.

In this article a novel methodology developed for the rigorous screening of $B$. braunii strains for their biofuel potential measurement is presented. It has to be considered as being complementary of a MTCS approach since it is designed from a process point of view. Indeed, this strategy was elaborated to allow the selection of the best strains in terms of culture robustness and biofuel molecular precursor productivity (namely TAG and HC) in highly controlled culture conditions. For that purpose, parallel mini PBR systems (efficient overproducing strain screening-PBR or EOSS-PBR) run in continuous mode with standardized cultivation medium were exploited in order to obtain comparable and unbiased productivity parameters (biomass and lipids of interest) [24]. To embrace the chemical potential of the tested strains, this was combined with an exhaustive high-throughput lipid class profiling methodology adapted to $B$. braunii, using high-performance thin layer chromatography (HPTLC). Results and perspectives emerging from this study are described and discussed in this manuscript.

\section{Material and methods}

\subsection{Chemicals and standards}

HPLC-grade solvents were purchased from VWR International. Butylated hydroxytoluene (BHT) was obtained from Sigma-Aldrich. All the lipid class standards (Table S1) and the chemicals used for HPTLC were commercially available, and obtained from Sigma-Aldrich, except glycolipids, which were supplied by Larodan. HPTLC glass plates $(20 \times 20 \mathrm{~mm})$ pre-coated 
with silica gel 60 were supplied by Merck \& Co., Ltd (Darmstadt, Germany).

\subsection{B. braunii strains}

The strains used for this study belong to the B. braunii species. A total of 10 strains were purchased from international algae banks (Algobank-Caen, France; CCAP, Scotland; CCALA, Czech Republic; and SAG, Germany). Table 1 summarizes the features and the codes used in this article.

\subsection{Cultivation in flasks}

Algal cells were cultivated in $250 \mathrm{~mL}$ Erlenmeyer flasks, under constant stirring at $75 \mathrm{rpm}$ and $25^{\circ} \mathrm{C}$, using fourfold-concentrated modified Chu 13 medium [10] with $15 \mathrm{mM}$ of $\mathrm{NaHCO}_{3}$ maintained at constant $\mathrm{pH} 7.4$ (maintained using $4 \% \mathrm{CO}_{2}$-enriched air bubbled at $20 \mathrm{~mL} \mathrm{~min}^{-1}$ ) and continuous illumination at approximately $80 \mu \mathrm{mol} \mathrm{m}^{-2} \mathrm{~s}^{-1}$.

\subsection{Cultivation in EOSS-PBR}

\subsubsection{EOSS-PBR system description}

The measurement of $B$. braunii cell growth and productivity was performed in EOSS-PBR [24]. It consisted of $2 \times 6$ small-scale PBR (bubble columns of $15 \mathrm{~mm}$ in internal diameter $\times 20 \mathrm{~cm}$ height) operated in parallel. Each PBR had a usable volume of $30 \mathrm{~mL}$ and an illuminated area of $0.008 \mathrm{~m}^{2}$. EOSS-PBR were fully automated in terms of medium injection and biomass harvesting to allow continuous cultivation, with the ability to set different feeding or harvesting sequences in each PBR. A sequence was defined by the feeding/harvesting flow rate, its time of application and duration. In order to compare the strains, identical parameters were applied for all the PBR. The maximum deviation in the daily dilution rates during the continuous cultivation in each PBR was lower than $10 \%$. For the cultivation, the basis of the medium was the classical Chu 13 , in which the concentration of all components was increased fourfold to avoid mineral limitation. The medium was also supplemented with carbon in one of the two manners: (1) directly in the medium as bicarbonates and (2) by bubbling $\mathrm{CO}_{2}$ into the culture. The $\mathrm{pH}$ was always stabilized at 7.4. The carbon supply was set to prevent growth limitation by the dissolved inorganic carbon. This was obtained by adding $15 \mathrm{mM}$ of $\mathrm{NaHCO}_{3}$ in culture medium with a constant bubbling in EOSS-PBR with $\mathrm{CO}_{2}$ enriched air $\left(4 \%\right.$ air $\left./ \mathrm{CO}_{2}\right)$ at a flow rate of $60 \mathrm{vv}^{-1} \mathrm{~h}^{-1}$. The gas flow rate was controlled and regulated by a mass flow meter (Bronkhorst). The gas injection located at the bottom of the PBR was found to be well adapted to $B$. braunii's physiology. Indeed, it managed the HC content decantation/floatability parameter and prevented also the colony from de-structuration that would generally result in immediate high mortality. The morphology integrity was found to be an essential parameter for the biomass survival $[32,33]$. The incident photon flux density (PFD) was provided by a set of $2 \times 6$ white fluorescent light tubes to obtain a continuous PFD of $100 \mu \mathrm{mol} \mathrm{m}^{-2} \mathrm{~s}^{-1}$.

\subsubsection{Conditions used for the batch culture mode}

For the first evaluation, all tested strains were grown in flasks in batch mode. Cultures were only limited by light but not by mineral or nutrient [34]. The EOSS-PBR were exposed to continuous illumination conditions, with PFD of $100 \mu \mathrm{mol} \mathrm{m}^{-2} \mathrm{~s}^{-1}$. Each culture was inoculated to reach an initial biomass concentration of $0.05 \pm 0.01 \mathrm{~g} \mathrm{~L}^{-1}$ and was monitored for 25 days. Turbidity was measured every 2 days for the first 10 days and then twice or thrice a day after reaching the late exponential phase and the early sta- tionary phase. The last sampling was used as described in Section 2.4.4 to correlate turbidity and DW concentration.

\subsubsection{Conditions used for the continuous culture mode}

During the first 4 days of the cultures in EOSS-PBR, a batch mode was applied. Each culture was inoculated to reach an initial biomass concentration of $0.05 \pm 0.01 \mathrm{~g} \mathrm{~L}^{-1}$. Then, when the biomass concentration was high enough (at least $1 \mathrm{~g} \mathrm{~L}^{-1}$ ), a continuous mode was applied with residence time of 4.2 days (i.e., a dilution rate of $0.010 \mathrm{~h}^{-1}$ ). This dilution rate was chosen to avoid culture washout. In addition, enough volume could be sampled for accurate measurement of biomass concentration and lipid analyses. The EOSS-PBR were exposed to constant culture conditions, with PFD of $100 \mu \mathrm{mol} \mathrm{m}^{-2} \mathrm{~s}^{-1}$ and were monitored for 16 days in continuous mode when steady state was achieved. Turbidity was measured once every day and microalgae sampled once for lipid analysis.

\subsubsection{DW biomass concentration measurement}

All analyses were performed in triplicate. Culture turbidity was assessed spectrophotometrically at $750 \mathrm{~nm}$. Algal DW were measured by filtration through a pre-dried and pre-weighed $0.2 \mu \mathrm{m}$ glass fiber filter (Whatman GF/F) using demineralized water as a washing buffer. The filter was then dried $24 \mathrm{~h}$ at $105^{\circ} \mathrm{C}$, cooled in a desiccator, and weighed again with an accuracy of $0.01 \mathrm{mg}$ on an XA105 analytical balance (Mettler-Toledo). For each biomass concentration, microalgae cells were also observed using an optical microscope (Carl Zeiss) to check colonial morphology integrity and stability during all the culture duration.

\subsection{Development of the HPTLC high-throughput method for B. braunii lipid class analysis}

\subsubsection{B. braunii biomass harvesting protocol}

A volume of culture (determined according to the biomass concentration) equivalent to $25 \mathrm{mg}$ of fresh biomass was harvested from each microalgae culture and frozen at $-80^{\circ} \mathrm{C}$. The frozen cultures (cells + media) were then lyophilized for $12 \mathrm{~h}$ at $4{ }^{\circ} \mathrm{C}(\mathrm{RP} 2 \mathrm{~V}$ Sérail SGD, Argenteuil, France) and stored at $-20^{\circ} \mathrm{C}$ before being subjected to the total lipid (TL) extraction protocol. This biomass sampling protocol was chosen, because it prevented possible leakage of the targeted metabolites that could occur during the cell harvesting procedure. It therefore ensured the acquisition of a faithful image of the compounds present in the analyzed matrix.

\subsubsection{TL extraction protocol}

The TL extraction protocol was developed for lyophilized $B$. braunii biomass as follows. The glassware was systematically heated for $6 \mathrm{~h}$ at $450^{\circ} \mathrm{C}$ to avoid organic pollution. $25 \mathrm{mg}$ of lyophilized biomass were aliquoted in glass vials, in triplicate, and assayed for TL extraction. It consisted in extracting the TL at once, including the targeted $\mathrm{HC}$, without considering its cellular localization, using a unique extracting solvent. It was adapted from the whole cell analytic method [35].

Lyophilisate was suspended in about four equivalent volumes of ultrapure water and $2 \mathrm{~mL}$ of chloroform:methanol mixture $(2: 1$, $\mathrm{v}: \mathrm{v})$ were added. The vials were then sonicated in a water bath $\left(20^{\circ} \mathrm{C}\right)$ and maintained for $2 \mathrm{~h}$ under agitation to ensure a complete lipid extraction. After centrifugation, the organic phase was removed and stored. In order to extract TL, this protocol was repeated four more times. Demixing was performed on the final $10 \mathrm{~mL}$ of organic pooled extracts by adding $2 \mathrm{~mL}$ of aqueous solution of $\mathrm{KCl}(0.8 \%)$ to remove the hydrophilic compounds from the TL extract solution. After decantation and adding BHT as antioxidant $(0.01 \% \mathrm{w} / \mathrm{w})$, the TL extract was evaporated to dryness under $\mathrm{N}_{2}$, weighted with an accuracy of $0.01 \mathrm{mg}$ (analytical balance 
Table 1

List of the strains screened in the present article. The origins of the strains are indicated for both bank of conservation and natural biotope of discovery.

\begin{tabular}{|c|c|c|c|c|}
\hline Code used in the present article & Original accession number & Bank of origin & Race & Natural biotope \\
\hline bb1 & 755 & Algobank & A & Small pond (15 ${ }^{\circ}, \mathrm{pH}$ 6.9) Lingoult (France) \\
\hline bb2 & 757 & Algobank & A & Small pond $\left(15^{\circ}, \mathrm{pH} 6.6\right)$ Oukaimden (Morocco) \\
\hline bb3 & 761 & Algobank & $\mathrm{B}$ & Small pond $\left(32^{\circ}, \mathrm{pH} 6.6\right)$ Paquemar (Martinique) \\
\hline bb4 & 30.81 & SAG & A & Cuzco Lake (Peru) \\
\hline bb5 & 777 & CCALA & - & Portugal \\
\hline bb6 & 778 & CCALA & - & Portugal \\
\hline bb7 & - & Confidential source & A & - \\
\hline bb8 & 835 & CCALA & A & Cuzco Lake (Peru) \\
\hline bb9 & $807 / 2$ & CCAP & A & Grasmere (England) \\
\hline bb10 & $807 / 1$ & CCAP & A & Cambridge (England) \\
\hline
\end{tabular}

XA105DU, Mettler-Toledo) and stored at $-20^{\circ} \mathrm{C}$ under nitrogen atmosphere prior to subsequent analysis.

\subsubsection{Choice of HPTLC quantification standards representative of \\ B. braunii lipid classes}

In order to limit the absolute quantification biases, it was mandatory to determine the molecular compounds that represented the most the targeted lipid classes, HC and TAG. For that purpose, solid-phase extraction fractionation was used allowing the separation of these relevant lipid classes. Each class was profiled, in terms of fatty acid (FA) composition for TAG and of HC composition, by gas chromatography coupled to a flame ionization detector (GC-FID) following the method described in detail in Moutel et al. [36]. This allowed determining the most abundant compounds, and choosing the most appropriate HPTLC quantification standards (data not shown). Substitution standards were used for the development of HC analysis method by HPTLC, because major HC compounds synthesized by $B$. braunii species were not commercially or academically available. Indeed, linear alkadienes or trienes (race A), botryococcenes (race B), or lycopadiene (race L) were no longer available from the unique known provider (Chiron $\mathrm{AS}^{\circledR}$, Trondheim, Norway). $\mathrm{N}$-alkane standard mixture $\left(\mathrm{C}_{10}-\mathrm{C}_{40}\right.$, all even), squalene, squalane and phytol were respectively chosen as substitutes for those molecules, because they possess the major structural elements found on the HC synthesized by B. braunii species (Table S2).

\subsubsection{HPTLC operational parameters}

2.5.4.1. Separation of B. braunii lipid classes by HPTLC. TAG, HC, and polar lipids (PL) were analyzed separately by HPTLC.

\section{- TAG}

TAG and other neutral lipid (ONL) classes were analyzed as described by Haberkorn et al. [37]. A preliminary run was conducted to remove possible impurities using hexane:diethyl ether $(97: 3, v: v)$, and the plate was activated for $30 \mathrm{~min}$ at $120^{\circ} \mathrm{C}$. Lipid samples were spotted on the plates by the CAMAG automatic sampler (CAMAG, Switzerland). A double development with two distinct solvent systems allowed the separation of TAG from the ONL classes. The first solvent system contained hexane:diethyl ether:acetic acid (20:5:0.5, v:v:v), whereas the second was composed of hexane:diethyl ether (97:3, v:v). After dipping plates in a copper sulfate-phosphoric acid solution and heating for $20 \mathrm{~min}$ at $160^{\circ} \mathrm{C}$ (charring), six NL classes (free FA), sterol esters, fatty alcohols, TAG, glyceride ethers, and free sterols appeared as black spots (Fig. S1A).

\section{- Hydrocarbons (HC)}

The above separation method did not permit the separation and the quantification of the $\mathrm{HC}$ from the TL extract of Botryococcus braunii. Indeed, HC being highly apolar, when compared with the aforementioned NL, they migrated with the solvent front. A specific HPTLC method was therefore developed to analyse and quantify the HC. It consists in improving the retention power of the stationary phase (through the increase of the activation temperature of the silica plate from 120 to $160^{\circ} \mathrm{C}$ ) and decreasing the polarity of the mobile phase (through the replacement of the hexane:diethyl ether:acetic acid (20:5:0.5, v:v:v) solvent system by hexane). These modifications allowed a clear separation of HC from the solvent front and from TAG and ONL. HC spots were then revealed after dipping and charring the plates, as with the TAG and ONL method (Fig. S1B).

\section{- Polar lipids (PL)}

PL were also analyzed as described by Haberkorn et al. [37], with the same activation and color development conditions as for TAG (30 min at $120^{\circ} \mathrm{C}$ and $20 \mathrm{~min}$ at $160^{\circ} \mathrm{C}$, respectively). The system solvent used for the pre-run and run was composed of methyl acetate:isopropanol:chloroform:methanol: $\mathrm{KCl}$ aqueous solution of $0.25 \%$ (10:10:10:4:3.6, v:v:v:v:v). This method, routinely used and adapted to marine animal matrices (mainly bivalves) [37-39], allowed the separation of not only the different phospholipid classes present in these matrices, cardiolipin (CL), sphingomyelin (SM), lysophosphatidylcholine (LPC), phosphatidylcholine (PC), phosphatidylethanolamine (PE), phosphatidylserine (PS), and phosphatidylinositol (PI), but also some particular microalgae glycolipids such as monogalactosyldiacylglycerol (MGDG) and digalactosyldiacylglycerol (DGDG). However, two PL classes, present in the microalgae $B$. braunii, sulfoquinovosyldiacylglycerol (SQDG) and phosphatidylglycerol (PG), were co-eluted with PE (Fig. S2).

In order to achieve the separation of SQDG and PG, two additional HPTLC methods were developed, each allowing the isolation of one of these lipid classes. These methods were similar to the previous one, except the pre-run and run solvent systems. The first method used methyl acetate:isopropanol:chloroform:methanol: $\mathrm{KCl}$ aqueous solution of 0.25\% (25: 25:25:10:4, v:v:v:v:v) for the pre-run and run. It allowed isolating SQDG, whereas $\mathrm{PE}+\mathrm{PG}$ as well as $\mathrm{PC}+\mathrm{PS}+\mathrm{LPC}+\mathrm{SM}$ were co-eluted (Fig. S3). The second method used methyl acetate:isopropanol:chloroform:methanol: $\mathrm{KCl}$ aqueous solution of $0.25 \%(25: 25: 25: 10: 4, v: v: v: v: v)$ for the pre-run and chloroform:methanol:ammonia water (65:30:4, v:v:v) for the run solvent system. It allowed isolating PG, whereas PE + SQDG + DGDG were co-eluted (Fig. S4). Only the combination of all of the three methods allowed the analysis of each of the PL classes of B. braunii.

2.5.4.2. Identification of braunii lipid classes. TAG, HC, ONL and PL spots were identified based on commercial standards (Table S1 and S2). Particularly, standards were chosen based on the microalgal nature (glycolipids) of the analyzed matrices and the 
biofuel profile of $B$. braunii (HC and FA composition of the different lipid classes). Phospholipid and glycolipid identification was confirmed by coloring techniques: orcinol for glycolipids, Dittmer and Lester's reagent for phospholipids [40], ninhydrine for amino acid containing molecules (PE and PS), and azure A for sulfolipids. In addition, because of the membrane lipid complex composition, a two-dimensional separation was performed to further confirm the identification of each PL class and to ensure that no pigments were co-eluted with PL (Figs. S5 and S6). The solvent system used for the one-dimensional pre-run migration was methyl acetate:isopropanol:chloroform:methanol: $\mathrm{KCl}$ aqueous solution of $0.25 \%(25: 25: 25: 10: 4, v: v: v: v: v)$, and the one used for the twodimensional migration (that is to say after a $90^{\circ}$ rotation of the plate) was chloroform:methanol:ammonia water (65:30:4, v:v:v).

2.5.4.3. Quantification of braunii lipid classes by scanning densitometry and external calibration. B. braunii lipid classes were quantified by scanning densitometry using winCATS software for data treatment (CAMAG, Switzerland). Charred plates were read at $370 \mathrm{~nm}$, and black spots were quantified by external calibration. Calibration curves were generated for each lipid class standard by spotting increasing amounts of the standard mixture solutions. A Michaelis-Menten-type regression analysis was used for the quantification of each lipid class (Fig. S7).

Results were expressed as class (PE, TAG, etc.), lipid fraction (PL, $\mathrm{NL}$, and $\mathrm{HC}$ ), or TL mass proportion, relatively to a particular lipid fraction, TL or biomass (DW).

\subsubsection{Statistical analysis of the experimental data}

Experimental data were semi-automatically analyzed, and the final data matrix (lipid classes and their relative or absolute abundance) was analyzed using R 3.1.2 statistical software with the FactoMineR package [41]. Data consistency was systematically assessed through multivariate analysis such as hierarchical clustering or principal component analysis (data not shown) and univariate descriptive methods such as data distribution summary or significance tests (boxplots, etc.).

\section{Results and discussion}

\subsection{Validation of the screening methodology}

The screening strategy was adapted to the physiological and chemical specificities of $B$. braunii in order to select under standardized cultivation condition the most robust strains with highest growth rate and highest TAG and HC productivities.

\subsubsection{Adaptation of the EOSS-PBR operational parameters to the physiological specificities of $B$. braunii strains}

The unique physiology of $B$. braunii required one to adapt the methodologies usually employed for microalgae culture and characterization. The following points were particularly investigated and improved.

\subsubsection{EOSS-PBR design. The EOSS-PBR was previously developed} for the screening of microalgae generally known for their potential in biodiesel production, such as Nannochloropsis [24]. The present study adapted this system to $B$. braunii, with only slightly adjusted mixing conditions. Indeed, as the colony integrity was described to be an essential parameter for culture survival [32,33], it was mandatory to set the gas injection flow from the bottom of the PBR at a value that prevents colony break-down, generally leading to immediate cell death and culture crash. It was set at $60 \mathrm{v} \mathrm{v}^{-1} \mathrm{~h}^{-1}$, allowing also the buoyancy of the colonies (varying accordingly to HC content).
3.1.1.2. Biomass concentration measurement. The measurement method of biomass concentration was also adapted. A DWturbidity correlation approach was developed, in order to minimize the sampling volume in the EOSS-PBR. Calibration and validation results (Figs. S8 and S9) indicated that it was possible to perform precise DW measurements in our PBR screening system irrespective of the variation of $B$. braunii morphology. The volume needed for the measurements was of $2 \mathrm{~mL}$, and the measurements were unrelated to particle size in the operational working range (i.e. below $3.5 \mathrm{~g} \mathrm{~L}^{-1}$ ).

\subsubsection{Lipid class separation, identification and quantification by HPTLC}

The development of an exhaustive quantitative profiling method of the lipid classes of B. braunii was performed as following. The repeatability of the TL extraction protocol was first estimated by the relative standard deviation ( RSD $<6 \%$ ) and its efficiency and fidelity was found to be unrelated to the tested strains as also demonstrated in Moutel et al. [36] (data not shown). Lipid class identification by HPTLC could be therefore envisaged since chemical images of comparable quality could be obtained. This was achieved directly on the TL extract using multiple and complementary HPTLC separation methods. Two systems were developed for the analysis of the biofuel lipids namely TAG and HC (Fig. S1). Concerning the identification of the PL classes, more complex separation methods were developed. For a complete profiling, three one-dimensional migration systems, completed by a higherresolution two-dimensional migration system were needed (Fig. S6). It was important to focus on the quality of the separation since it would greatly influence the accuracy of the quantitative data gathered after integration of the HPTLC signal.

The absolute quantification of the classes of interest was developed in order to limit the biases of the external calibration approach. For that purpose molecular composition of the TL extract was determined and the most abundant compound was chosen as external standard. The dynamical ranges obtained for the quantification of the targeted classes of interest (TAG and HC) were adapted to $B$. braunii lipid profile and to our operational conditions (i.e. ranging from 10 to $1000 \mathrm{ng} \mu \mathrm{L}^{-1}$ ) (Fig. S7). The distribution of RSD of the quantification results obtained for each class mixed together and calculated for an independent triplicate was centered at approximately $30 \%$. HPTLC approach was thus less repeatable than other chromatographic methods (with RSD usually found at 10\%), accurately targeting compounds of interest, such as FA or HC, by GC-FID. This lack of repeatability, that was still acceptable, was however counterbalanced by the HPTLC high-throughput advantage, and was therefore perfectly adapted to the requirements of a rapid quantitative screening methodology.

\subsection{Prescreening of the $\mathrm{B}$. braunii strains according to biomass productivity and lipid content in a small-scale EOSS-PBR system}

\subsubsection{Activation of microalgae growth ability in flask run in \\ batch mode}

In order to provide enough and similar biomass quantity for EOSS-PBR inoculation, the 10 strains were initially cultivated in flasks. Lag phases were different for each strain, varying from few days to several weeks (not shown). Finally, 8 out of the 10 strains grew well in these conditions. Only the strains bb4 and bb9 never demonstrated a clear ability to grow. DW biomass concentration remained very low, and reached a maximum value of $0.01 \mathrm{~g} \mathrm{~L}^{-1}$. The other strains, bb1, 2, 3, 5, 6, 7, 8, and 10 reached a DW biomass concentration which allowed an inoculation in EOSS-PBR. 


\subsubsection{Quantitative and qualitative characterization of the 8} remaining strains grown under high-DIC conditions in EOSS-PBR run in batch mode

Although all strains were issued from the same species, results indicated that there was a large variation in growth kinetics (Fig. 2). All the cultures were inoculated with the same biomass DW concentration, $0.15 \mathrm{~g} \mathrm{~L}^{-1}$. Lag phase in batch culture conditions differed widely, ranging from ca. 1 (bb1, 2, 3) to 8 days (bb5, 6, 7) (Table 2). The latter strains also presented very low biomass DW concentrations $\left(<0.2 \mathrm{~g} \mathrm{~L}^{-1}\right)$ at the end of the culture. In spite of its fast adaptation (short lag phase), the strain bb1, finally reached only $0.6 \mathrm{~g} \mathrm{~L}^{-1}$. The 8 strains were clustered into 2 groups based on their growth ability in batch mode. The first group (bb1, 5, 6, 7) exhibited low growth ability, whereas the second $(b b 2,3,8,10)$ exhibited high ability to grow, short lag phase time, and high final biomass concentration $\left(>3.5 \mathrm{~g} \mathrm{~L}^{-1}\right.$ ) (Table 2). For comparison with literature, the doubling time $\left(t_{d}\right)$ of cultures was also estimated. For microalgae, this value is difficult to be accurately determined, since it is highly influenced by culture conditions and more especially by light attenuation conditions which differ most of the time according to the experiments and studies (i.e. different light intensity, biomass concentration and/or geometries of culture vessels). In addition, as a consequence of the low volume of the EOSS PBR incompatible with daily sampling, only an estimation of $t_{d}$ values could be here provided. Keeping in mind that consideration, interpretation of estimated $t_{\mathrm{d}}$ values gave however consistent tendencies. The strains bb2, 3, 8, and 10 showed minimal estimated $t_{\mathrm{d}}$ varying from 1.1 to 2 days. The estimated $t_{\mathrm{d}}$ of 1.1 days for the bb10 strain cultivated under continuous illumination appeared to be close to the minimal $t_{\mathrm{d}}$ reported in the literature but for B. braunii B-race cultivated following light-dark cycle of $14 \mathrm{~h}: 10 \mathrm{~h}$ (1.4 days) [42]. For comparison purpose, the same A-race strain (bb10) studied by Kalacheva et al. [43], was previously shown to present, when grown in a similar cultivation medium (except for the microelement solution, containing $\mathrm{Ni}$ in their experiment), a $t_{\mathrm{d}}$ of 2.9 days for an average biomass DW productivity of $0.16 \mathrm{~g} \mathrm{~L}^{-1} \mathrm{day}^{-1}$. The main difference was that these authors cultivated the microalgae semi-continuously in conical flasks under $1 \% \mathrm{CO}_{2}$ and not in continuous PBR. The $t_{\mathrm{d}}$ values estimated in our study were close to those measured in the literature and appeared to be very encouraging. However, they need to be confirmed using large scale PBR, with larger sampling volume capacity notably [4]. The growth curves of the 8 strains (Fig. 2) were also compared to a reference, a PBR culture of the strain bb10 (807/1) previously performed in batch mode [20]. Although culture conditions were not adapted, in the present screening system configuration, for each of the tested strains, similar growth patterns were obtained (to that of 4 of the tested strains), but with higher growth features, ending at $4 \mathrm{~g} \mathrm{~L}^{-1}$, suggesting that the EOSS PBR screening culture system in its tested setup was well adapted to $B$. braunii physiology.

$B$. braunii lipid class content was also assessed on the tested strains using the previously described HPTLC methods. In terms of HC content, results differed from those of literature. Only bb7 contained more than 23\% DW of HC under high-DIC conditions in EOSS-PBR run in batch mode (Table 2). The variability of HC contents in the tested strains was in agreement with those reported in the literature as depicted in Fig. 1. The measured TL content ranged from 13 to $34 \% \mathrm{DW}$ in the tested conditions. For the fast-growing strains, TL content was comprised between 21 and 32\% DW and was, surprisingly, dominated by TAG which ranged from 11 to $21 \%$ DW. PL accounted for 1-6\% DW for all the tested strains, which was consistent to what was generally observed for other microalgae species [44]. Those results highlighted that $B$. braunii biofuel potential, so far mainly focused on HC, should also be investigated for its TAG content.
For the rest of the study, efforts were focused on the evaluation of the fast-growing strain group - i.e. strains that are able to grow in large scale PBR -, which was composed of the strains bb2, bb3, bb8, and bb10.

\subsection{Measurement of HC and TAG productivity of the four B. braunii selected strains cultivated in EOSS-PBR run in continuous mode}

The 4 strains selected during the prescreening step were cultivated in EOSS-PBR in continuous mode in order to compare both their biomass DW productivity and their lipid composition. Because of the negative correlation between growth and light attenuation conditions, biomass DW productivity was the most unbiased way to compare microalgal growth in PBR, and should always be preferred to the use of the maximum specific growth rate $\left(\mu_{\max }\right)$. Indeed, by definition $\mu_{\max }$ can be achieved in non-limiting growth conditions and thus only with negligible light attenuation in the culture volume. As light attenuation depends on the biomass density, it can only be reached for low cell concentration, which is however not representative of a culture growth in PBR [24]. In addition, in continuous mode, it is also well-known that the specific growth rate is equal at steady-state to the dilution rate $\left(0.01 \mathrm{~h}^{-1}\right.$ in our case) which is a non-biological value imposed onto the PBR by the feeding-harvesting flow rate. As a consequence, only productivity (P) that takes into account both dilution rate (D) and steady state concentrations (C) (i.e. $P=D . C$ ) allows the quantification of the potential of the most productive strain in terms of HC and TAG productivities.

\subsubsection{Biomass productivity and microalgae ability to grow in EOSS-PBR run in continuous mode}

The biomass from the previous flask cultures was inoculated in EOSS-PBR. Adaptation time was shorter as compared to highDIC culture conditions, as no or very short lag phase was observed (Fig. 3). For all strains, a high biomass concentration was rapidly reached (for example, $2.6 \mathrm{~g} \mathrm{~L}^{-1}$ was obtained for the strain bb3), allowing switching to continuous cultivation mode after $c a$. 3 days. A steady state was reached after $\mathrm{ca}$. 12 days of stabilization, corresponding to approximately threefold the residence time. As emphasized in Taleb et al. [24], stable biomass productivities obtained in continuous culture mode allow reliable biochemical characterization, in contrast to batch cultures, where adaptation phases could influence biomass productivity.

Only two strains (bb2 and bb3) exhibited stable steady state behavior in the applied conditions, with DW concentrations of 1.21 and $1.42 \mathrm{~g} \mathrm{~L}^{-1}$ for bb2 and bb3, respectively. Strain bb8 did not get over a maximum value of $0.34 \mathrm{~g} \mathrm{~L}^{-1}$ of biomass DW concentration, and bb10 lost its ability to grow in the EOSS-PBR airlift conditions after 11 days (Fig. 3). For the latter, a biomass concentration of $1.06 \mathrm{~g} \mathrm{~L}^{-1}$ was considered to calculate the productivity. Values of biomass productivity $\left(P_{\mathrm{x}}\right)$ varied from 74 to $307 \mathrm{mg} \mathrm{L}^{-1} \mathrm{day}^{-1}$ (Table 3 ), and indicated that bb3 was the most productive strain, followed by bb2, bb10, and bb8. All preselected strains, except bb10, seemed thus to be robust enough to undergo cultivation in PBR. Overall, those results illustrated the clear ability of the strains bb2 and bb3 to grow in controlled and intensified PBR culture conditions.

\subsubsection{TAG and HC productivities in EOSS-PBR run in continuous mode}

The productivities calculated for the strains grown in continuous mode in EOSS-PBR were also expressed according to the major compounds of biofuel interest, which are TAG and HC. Strain bb3 which clearly exhibited the best DW biomass productivity $\left(P_{\mathrm{X}}=307 \mathrm{mg} \mathrm{L}^{-1}\right.$ day $\left.^{-1}\right)$, presented HC $\left(P_{\mathrm{HC}}\right)$ and TAG $\left(P_{\mathrm{TAG}}\right)$ produc- 


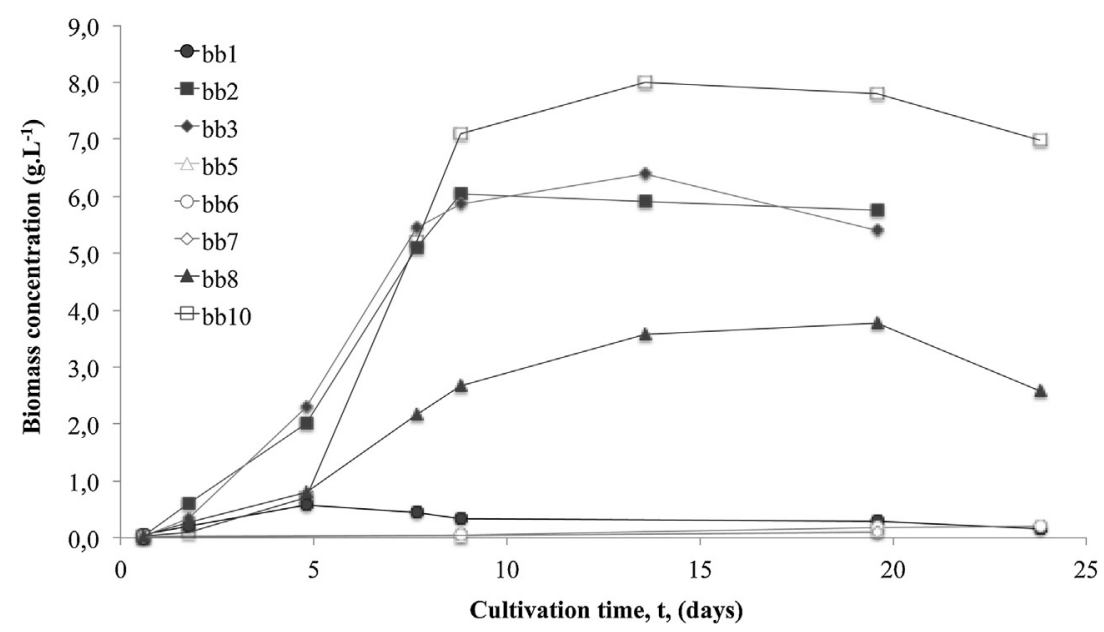

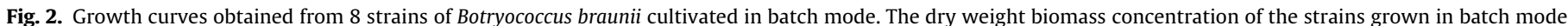
under high dissolved inorganic carbon conditions are indicated according to the days of sampling.

Table 2

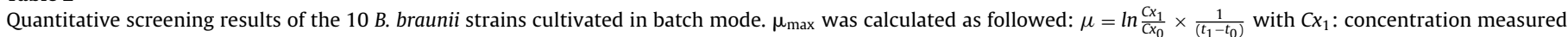

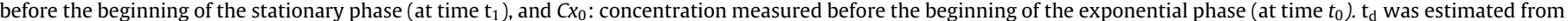
$\mu_{\max }$ using $t_{d}=\ln 2 /\left(\mu_{\max } \times 24\right)$. Px was calculated on the first 20 days of the culture.

\begin{tabular}{|c|c|c|c|c|c|c|c|c|c|c|c|c|}
\hline Strain & bb1 & bb2 & bb3 & bb4 & bb5 & bb6 & bb7 & bb8 & bb9 & bb10 & Mean & Standard deviation \\
\hline GROWTH & & & & No growth in flask & & & & & No growth in flask & & & \\
\hline$t_{d}(\mathrm{~d})$ & 1.9 & 1.9 & 1.5 & & 14.7 & 9.2 & 14.2 & 2.0 & & 1.1 & 5.8 & 5.6 \\
\hline$C x \max \left(g \mathbf{L}^{-1}\right)$ & 0.6 & 6.1 & 6.4 & & 0.1 & 0.2 & 0.1 & 3.8 & & 8 & 3.2 & 3.1 \\
\hline $\mathbf{P}_{\boldsymbol{x}}\left(\mathrm{mg} \mathbf{L}^{-1} \mathbf{d a y}^{-1}\right)$ & 13 & 300 & 281 & & 4 & 7 & 3 & 195 & & 408 & 151.4 & 154.3 \\
\hline $\begin{array}{l}\mu_{\max }\left(h^{-1}\right) \\
\text { LIPIDS (\%DW) }\end{array}$ & 0.015 & 0.015 & 0.020 & & 0.002 & 0.003 & 0.002 & 0.015 & & 0.026 & 0.0 & 0.0 \\
\hline TL & 27 & 21 & 32 & & 13 & 16 & 34 & 24 & & 22 & 23.6 & 6.8 \\
\hline NL & 21 & 20 & 28 & & 8 & 10 & 30 & 20 & & 16 & 19.1 & 7.2 \\
\hline HC & 1.4 & 2.9 & 2.0 & & 1.5 & 3.7 & 23.0 & 0.9 & & 3.6 & 4.9 & 6.9 \\
\hline TAG & 15.0 & 15.0 & 21.0 & & 3.0 & 1.0 & 2 & 15.0 & & 11 & 10.4 & 7.0 \\
\hline ONL & 4.6 & 2.1 & 5.0 & & 3.5 & 5.3 & 5 & 4.1 & & 1.4 & 4.5 & 1.6 \\
\hline PL & 6.0 & 1.0 & 4.0 & & 5.0 & 6.0 & 4.0 & 4.0 & & 6.0 & 3.9 & 1.3 \\
\hline
\end{tabular}

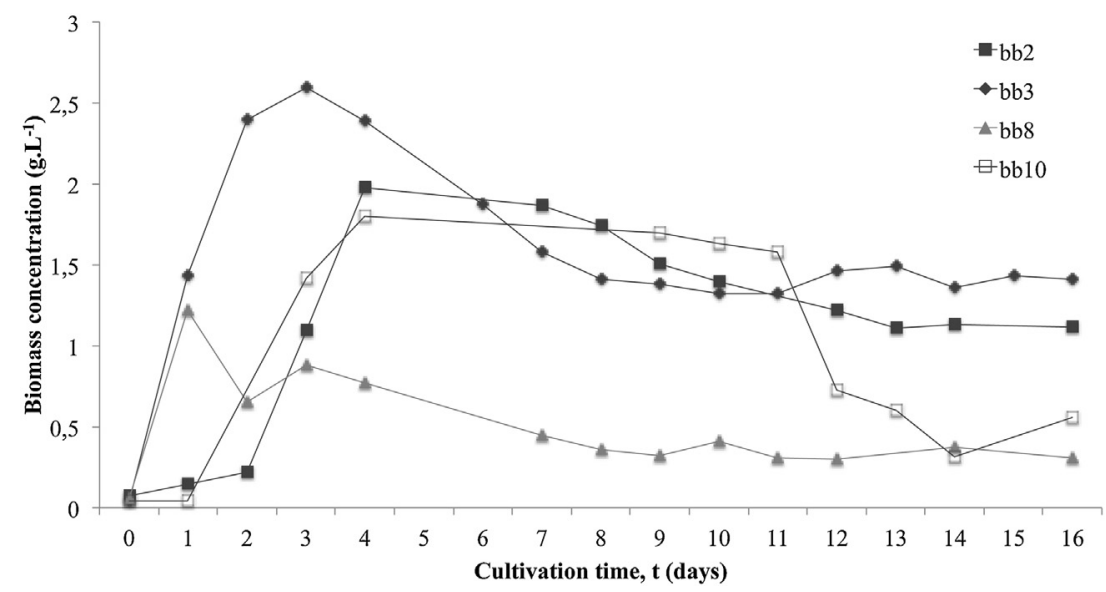

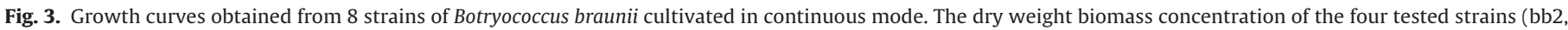
3,8 and 10) grown in continuous mode under high dissolved inorganic carbon conditions are indicated according to the days of sampling.

tivities of $14 \mathrm{mg} \mathrm{L}^{-1} \mathrm{day}^{-1}$ and $21 \mathrm{mg} \mathrm{L}^{-1} \mathrm{day}^{-1}$, respectively. Those productivities were compared to the literature. However, very few studies performed continuous culture of $B$. braunii, making a definitive conclusion difficult to reach at this stage. Khatri et al. [29] recently obtained a $P_{\mathrm{TAG}}$ of $22.5 \mathrm{mg} \mathrm{L}^{-1} \mathrm{~h}^{-1}{ }_{-} \sim 540 \mathrm{mg} \mathrm{L}^{-1} \mathrm{day}^{-1}{ }_{-}$, which was much higher than the one achieved in the present study.
However, culture conditions were greatly different, since those authors performed a high-cell density culture of $B$. braunii, obtained using high light exposure ( $\sim 1 / 4$ full sun for $\left.15 \mathrm{~h} \mathrm{day}^{-1}\right)$ and thinfilm culture. Such conditions are known to lead to high volumetric productivity. As demonstrated by Pruvost and Cornet [23], with an appropriate definition of those parameters (i.e. incident light, 

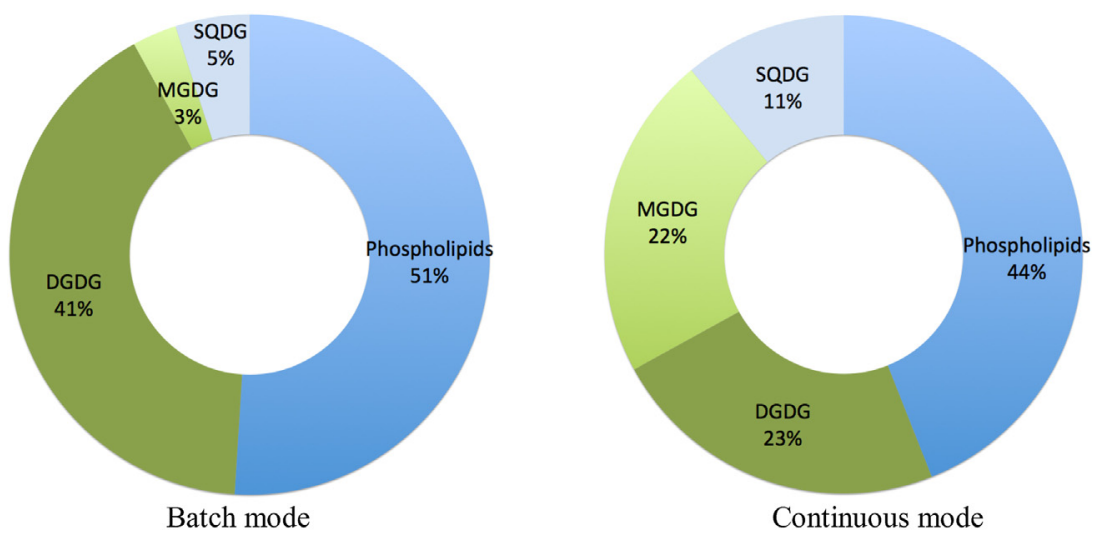

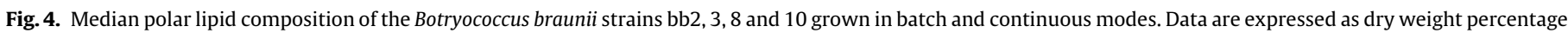
(DW\%).

\section{Table 3}

Quantitative screening results of the four Botryococcus braunii selected strains (bb2, 3,8 and 10) cultivated in continuous mode. Biomass, HC and TAG productivities values are indicated, together with the final lipids composition measured at the end of the culture.

\begin{tabular}{lllll}
\hline Strain & bb2 & bb3 & bb8 & bb10 \\
\hline PRODUCTIVITY & & & & \\
CX $\left(\mathrm{g} \mathrm{L}^{-1}\right)$ & 1.21 & 1.42 & 0.34 & 1.06 \\
$P \mathrm{PX}\left(\mathrm{mg} \mathrm{L}^{-1} \mathrm{day}^{-1}\right)$ & 262 & 307 & 74 & 204 \\
$P_{\mathrm{HC}}\left(\mathrm{mg} \mathrm{L}^{-1} \mathrm{day}^{-1}\right)$ & 9 & 14 & 1 & 5 \\
$P_{\mathrm{TAG}}\left(\mathrm{mg} \mathrm{L}^{-1} \mathrm{day}^{-1}\right)$ & 15 & 21 & 3 & 10 \\
LIPIDS $(\% \mathrm{DW})$ & & & & \\
TL & 23.0 & 20.0 & 18.0 & 23.0 \\
NL & 14.5 & 15.1 & 11.6 & 13.6 \\
HC & 3.3 & 4.6 & 1.4 & 2.3 \\
TAG & 6.0 & 7.0 & 4.0 & 5.0 \\
$\quad$ ONL & 5.2 & 3.5 & 6.2 & 6.3 \\
PL & 8.5 & 4.9 & 6.4 & 9.4 \\
\hline
\end{tabular}

culture depth), volumetric productivity for a given strain can be increased by two-orders of magnitude. Casadevall et al. [20,45] used conditions closed to those of the present study (identical dilution rate) and obtained $P_{\mathrm{x}}$ ranging from 180 to $373 \mathrm{mg} \mathrm{L}^{-1}$ day ${ }^{-1}$. The corresponding $P_{\mathrm{HC}}$ ranged from 20 to $97 \mathrm{mg} \mathrm{L}^{-1} \mathrm{day}^{-1}$, which corresponded to $\mathrm{HC}$ content of $26.1 \% \mathrm{DW}$ and $11.2 \% \mathrm{DW}$, respectively. These values are consistent with what was measured here in the EOSS-PBR conditions $\left(14 \mathrm{mg} \mathrm{L}^{-1}\right.$ day $\left.^{-1}\right)$, even though the final $\mathrm{HC}$ content was lower as compared to the values in the literature (Fig. 1). In the present study, HC production was obtained without inducing a nutrient stress, contrarily to what is generally done for TAG production in other species. This emphasizes the interest of $B$. braunii species for lipid production as their $P_{\mathrm{TAG}}$ are close to those of species known to produce high amount of TAG. For example, $P_{\mathrm{TAG}}$ of the strain bb3 was higher $\left(21 \mathrm{mg} \mathrm{L}^{-1} \mathrm{day}^{-} 1\right)$ than the maximal $P_{\mathrm{TAG}}$ of Nannochloropsis gaditana and Nannochloropsis salina obtained in the same EOSS-PBR cultivation system (13 and $18 \mathrm{mg} \mathrm{L}^{-1} \mathrm{day}^{-1}$, respectively) [24]. In addition, the natural ability of $B$. braunii to produce $\mathrm{HC}$ while growing allows setting continuous process, as it was confirmed here.

\subsubsection{TL class composition in EOSS-PBR run in continuous mode}

For the four selected strains (bb2, 3, 8 and 10), the median TL content was similar to what was measured during the prescreening step performed in batch mode. However, differences were observed in terms of lipid class composition. Table 4 illus- trates the relative median lipid composition obtained in batch and continuous modes. The median was used here in order to get robust statistical position parameters allowing comparison.

The median relative compositions in lipid classes revealed significant fold changes for the PL and TAG classes (1.88 and 0.52, respectively), when switching from batch to continuous culture condition mode in the EOSS-PBR. Such changes may reflect a physiological acclimation or adaptation to culture conditions. Access to light is considered to be the main difference between these two culture conditions [24]. Similar finding was already observed in the case of other microalgae grown under physiological nitrogen starvation [46]. The increase of the TAG/PL ratio in batch condition (which is equivalent to a stationary phase) as compared to continuous condition (which is equivalent to an exponential phase) was previously reported in other microalgae species when cultivated under nitrogen starvation. Reduction of light access was hypothesized to explain the observed metabolic shift converting chloroplastic lipids into TAG. When grown in continuous mode, $B$. braunii would increase the biosynthesis rate of the PL classes, apparently to the detriment of the TAG one. In order to address this question the detailed PL class composition was further explored and compared between continuous and batch conditions (Fig. 4). Major changes were observed in the proportions of MGDG and DGDG among PL, two major chloroplast lipids: the DGDG/MGDG ratio decreased from 13.7 in batch mode to 10.1 in continuous mode.

Such a strong modification in the MGDG/DGDG ratio was previously described for higher plants undergoing freezing or drought stress. In those cases, a certain proportion of MGDG was converted to DGDG and oligogalactolipids to prevent fissions and fusions of chloroplast membranes [47]. Similar modulation could also be observed under phosphate-limiting conditions with decreasing amounts of phospholipids, increasing amounts of DGDG and SQDG, and maintaining constant amount of MGDG [48]. Considering that access to light was typically inconstant in batch mode as compared to light attenuation in continuous culture conditions [49], observed modulation of the MGDG/DGDG ratio may reflect some membrane composition adjustments due to modified light access condition in PBR [50,51].

Finally, the glycolipid SQDG, which abundance increased ca. 2 times from batch to continuous culture mode (from 5\% of the PL to $11 \%$ ) (Fig. 4), is another chemical family of unique compounds of pharmaceutical interest to be investigated in the Botryococcus genus [52,53]. Indeed, previous studies performed on compounds of similar classes - i.e. glyco and sulfolipids - but originating 
Table 4

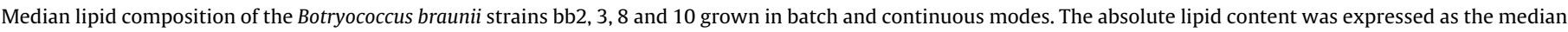

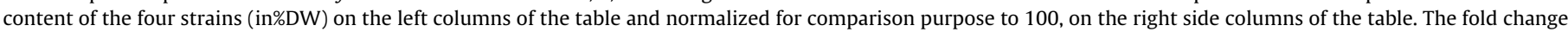
was calculated as the ratio of the normalized values continuous $v s$ batch.

\begin{tabular}{|c|c|c|c|c|c|c|}
\hline Lipid content (\%DW) & Continuous & Batch & Relative lipid content & Continuous & Batch & Fold change \\
\hline $\mathrm{TL}$ & 22 & 23 & $\mathrm{TL}$ & 100 & 100 & 1.00 \\
\hline $\mathrm{NL}$ & 15 & 19 & NL & 68 & 82 & 0.83 \\
\hline $\mathrm{HC}$ & 3 & 3 & $\mathrm{HC}$ & 14 & 13 & 1.08 \\
\hline TAG & 6 & 12 & TAG & 27 & 52 & 0.52 \\
\hline ONL & 6 & 4 & ONL & 27 & 17 & 1.59 \\
\hline PL & 7 & 4 & PL & 32 & 17 & 1.88 \\
\hline
\end{tabular}

from different bio-ressources revealed that such molecules could be interesting candidates to be investigated for their potential anti-inflammatory [54], anti-tumor [55], anti-angiogenesis [56,57] (glycolipids) or immunosuppressive activities [58] (sulfolipids).

\section{Conclusion}

In this article, it has been demonstrated that it is possible to develop a sensitive and rapid microalgae strain screening approach to assess the biofuel potential of Botryococcus. The strategy, using the EOSS-PBR combined with an exhaustive lipid class chemotyping approach using HPTLC was adapted to the particular physiology of Botryococcus. The obtained results revealed that growth performances and lipid profiles of $B$. braunii varied greatly according to the tested strains in the chosen screening conditions. Only two strains among the 10 tested were able to grow efficiently in a controlled environment, together with good quantitative productivity parameters, for both HC (for biokerosene) and TAG (for biodiesel). Under continuous lighting conditions, the strain bb3 exhibited the best results in terms of $P_{\mathrm{X}}$ (307 $\left.\mathrm{mg} \mathrm{L}^{-1} \mathrm{day}^{-1}\right)$ and was also the best performing one in terms of $P_{\mathrm{HC}}\left(14 \mathrm{mg} \mathrm{L}^{-1} \mathrm{day}^{-1}\right)$ and $P_{\mathrm{TAG}}\left(21 \mathrm{mg} \mathrm{L}^{-1} \mathrm{day}^{-1}\right)$. Those values were found to be close to those obtained with microalgae strains that are known to display high $P_{\text {TAG }}$ (around 13-18 $\mathrm{mg} \mathrm{L}^{-1}$ day $^{-1}$ for Nannochloropsis cultivated in the same EOSS-PBR). However, contrary to TAG-accumulating strains which involve applying $\mathrm{N}$-depletion to trigger TAG accumulation, HC production from $B$. braunii was obtained in continuous mode, because of the "natural" ability of $B$. braunii to produce HC while growing.

The developed approach also revealed the interest of using a lower resolution analytical technique for rapid chemotyping purposes, as compared with the classical gas chromatography coupled to mass spectrometry technique. Indeed, even though the fine structure of the major produced compounds could not be elucidated, it was still possible to detect lipid classes overexpressed in the tested cultivation conditions, and therefore to identify new families of chemical compounds to be investigated. Among the PL, SQDG abundance was found to increase in continuous cultures, suggesting that it could present interesting pharmaceutical applications, notably as potential anti-tumoral, anti-inflammatory or immunosuppressive agent. Moreover, our results led to hypothesize that $B$. braunii is able to adjust its chloroplastic lipid composition upon change in light conditions. Those hypotheses deserve to be further explored and confirmed as they may lead to improve the cultivation processes [59]. Finally, when combined with the previous study of Taleb et al. [24], those results suggest that this methodology could be generalized to other microalgae genera, according to their physiological particularities.

In the near future, this screening strategy could be used in combination with a MTCS-like approach using the next generation of EOSS-PBR-named EOSS-PBR-2-. Using EOSS-PBR-2, biotic and abiotic parameters could be optimized in order to enhance both $P_{\mathrm{HC}}$ and $P_{\mathrm{TAG}}$, as performed for the study of the influence of the incident light parameter in Sakamoto et al. [60]. Once established, those new parameters would enable pilot and largescale process studies to confirm the performances of the selected strains.

\section{Authors' contribution}

Benjamin Moutel, Fabienne Le Grand, and Olivier Gonçalves contributed to the experimental section and wrote the manuscript.

Dominique Grizeau, Philippe Soudant, and Jack Legrand contributed to the final approval of the article.

Dominique Grizeau, Olivier Gonçalves, and Jérémy Pruvost supervised the work.

\section{Acknowledgments}

Part of this work was funded by the CAER project (alternative fuel for aeronautics) and AIRBUS GROUP (Benjamin Moutel CIFRE Grant). EOSS-PBR was funded by the French National Research Agency project DIESALG (ANR-12-BIME-0001-02).

\section{Appendix A. Supplementary data}

Supplementary data associated with this article can be found, in the online version, at http://dx.doi.org/10.1016/j.procbio.2016.05. 002 .

\section{References}

[1] R. Razeghifard, Algal biofuels, Photosynth. Res. 117 (2013) 207-219.

[2] L.V. Wake, L.W. Hillen, Nature and hydrocarbon content of blooms of the alga Botryococcus braunii occuring in Australian freshwater lakes, Mar. Freshw. Res. 32 (1981) 353-367.

[3] A. Kadouri, S. Derenne, C. Largeau, E. Casadevall, C. Berkaloff, Resistant biopolymer in the outer walls of Botryococcus braunii, B race, Phytochemistry 27 (1988) 551-557.

[4] A. Banerjee, R. Sharma, Y. Chisti, U.C. Banerjee, Botryococcus braunii: renewable source of hydrocarbons and other chemicals, Crit. Rev. Biotechnol. 22 (2002) 245-279.

[5] P. Metzger, Y. Pouet, R. Summons, Chemotaxonomic evidence for the similarity between Botryococcus braunii L race and Botryococcus neglectus, Phytochemistry 44 (1997) 1071-1075.

[6] P. Metzger, C. Berkaloff, E. Casadevall, A. Coute, Alkadiene- and botryococcene-producing races of wild strains of Botryococcus braunii, Phytochemistry 24 (1985) 2305-2312.

[7] P. Metzger, A. Aumelas, A. Lycopanerols, di-Tetraterpenoid tetraether derivatives from the Green Microalga Botryococcus braunii L strain, Tetrahedron Lett. 38 (1997) 2977-2980.

[8] J.H. Belcher, Notes on the physiology of Botryococcus braunii Kützing, Arch. Microbiol. 61 (1968) 335-346.

[9] J. Komárek, P. Marvan, Morphological differences in natural populations of the genus Botryococcus (Chlorophyceae), Arch. für Protistenkunde 141 (1992) 65-100.

[10] C. Largeau, E. Casadevall, C. Berkaloff, The biosynthesis of long-chain hydrocarbons in the green alga Botryococcus braunii, Phytochemistry 19 (1980) 1081-1085.

[11] M. Azma, M.S. Mohamed, R. Mohamad, R.A. Rahim, A.B. Ariff, Improvement of medium composition for heterotrophic cultivation of green microalgae, Tetraselmis suecica, using response surface methodology, Biochem. Eng. J. 53 (2011) 187-195. 
[12] J. Van Wagenen, S.L. Holdt, D. De Francisci, B. Valverde-Pérez, B.G. Plósz, I. Angelidaki, Microplate-based method for high-throughput screening of microalgae growth potential, Bioresour. Technol. 169 (2014) 566-572.

[13] J. Wolf, I.L. Ross, K.A. Radzun, G. Jakob, E. Stephens, B. Hankamer, High-throughput screen for high performance microalgae strain selection and integrated media design, Algal Res. 11 (2015) 313-325.

[14] Y. Tanabe, S. Kato, H. Matsuura, M.M. Watanabe, A botryococcus strain with bacterial ectosymbionts grows fast and produces high amount of hydrocarbons, Proced. Environ. Sci. 15 (2012) 22-26.

[15] C. Gudin, D. Chaumont, For a solar biotechnology based on microalgae, in: P. Chartier, W. Palz (Eds.), Energy from Biomass, vol. 1, Springer Netherlands, 1981, pp. 81-84.

[16] P. Metzger, M.-N. Rager, C. Largeau, Polyacetals based on polymethylsqualene diols, precursors of algaenan in Botryococcus braunii race B, Org. Geochem. 38 (2007) 566-581.

[17] P. Metzger, M.-N. Rager, C. Fosse, Braunicetals: acetals from condensation of macrocyclic aldehydes and terpene diols in Botryococcus braunii, Phytochemistry 69 (2008) 2380-2386.

[18] E. Kojima, K. Zhang, Growth and hydrocarbon production of microalga Botryococcus braunii in bubble column photobioreactors, J. Biosci. Bioeng. 87 (1999) 811-815.

[19] C. Chirac, E. Casadevall, C. Largeau, P. Metzger, bacterial influence upon growth and hydrocarbon production of the green alga Botryococcus Braunii L, J. Phycol. 21 (1985) 380-387.

[20] E. Casadevall, D. Dif, C. Largeau, C. Gudin, D. Chaumont, O. Desanti, Studies on batch and continuous cultures of Botryococcus braunii: hydrocarbon production in relation to physiological state, cell ultrastructure, and phosphate nutrition, Biotechnol. Bioeng. 27 (1985) 286-295.

[21] R. Shimamura, S. Watanabe, Y. Sakakura, M. Shiho, K. Kaya, M.M. Watanabe, Development of botryococcus seed culture system for future mass culture, Proced. Environ. Sci. 15 (2012) 80-89.

[22] G. Van Vooren, F. Le Grand, J. Legrand, S. Cuine, G. Peltier, J. Pruvost, Investigation of fatty acids accumulation in nannochloropsis oculata for biodiesel application, Bioresour. Technol. 124 (2012) 421-432.

[23] J. Pruvost J.-F. Cornet, Knowledge models for the engineering and optimization of photobioreactors, Microalgal Biotechnology: Potential and Production: Posten Christian Clemens/Walter 2012 181-224.

[24] A. Taleb, J. Pruvost, J. Legrand, H. Marec, B. Le-Gouic, B. Mirabella, B. Legeret, S. Bouvet, G. Peltier, Y. Li-Beisson, S. Taha, H. Takache, Development and validation of a screening procedure of microalgae for biodiesel production: application to the genus of marine microalgae Nannochloropsis, Bioresour. Technol. 177 (2015) 224-232.

[25] L. Xu, R. Liu, F. Wang, C.Z. Liu, Development of a draft-tube airlift bioreactor for Botryococcus braunii with an optimized inner structure using computational fluid dynamics, Bioresour. Technol. 119 (2012) 300-305.

[26] Y. Shen, H. Zhang, X. Xu, X. Lin, Biofilm formation and lipid accumulation of attached culture of Botryococcus braunii, Bioprocess Biosyst. Eng. 38 (2015) $481-488$.

[27] A. Ozkan, K. Kinney, L. Katz, H. Berberoglu, Reduction of water and energy requirement of algae cultivation using an algae biofilm photobioreactor, Bioresour. Technol. 114 (2012) 542-548.

[28] H.S. Kim, T.L. Weiss, H.R. Thapa, T.P. Devarenne, A. Han, A microfluidic photobioreactor array demonstrating high-throughput screening for microalgal oil production, Lab Chip 14 (2014) 1415-1425.

[29] W. Khatri, R. Hendrix, T. Niehaus, J. Chappell, W.R. Curtis, Hydrocarbon production in high density Botryococcus braunii race B continuous culture, Biotechnol. Bioeng. 111 (2014) 493-503.

[30] R. Honda, J. Boonnorat, C. Chiemchaisri, W. Chiemchaisri, K. Yamamoto, Carbon dioxide capture and nutrients removal utilizing treated sewage by concentrated microalgae cultivation in a membrane photobioreactor, Bioresour. Technol. 125 (2012) 59-64.

[31] P. Cheng, B. Ji, L. Gao, W. Zhang, J. Wang, T. Liu, The growth, lipid and hydrocarbon production of Botryococcus braunii with attached cultivation, Bioresour. Technol. 138 (2013) 95-100.

[32] N. Plain, C. Largeau, S. Derenne, A. Couté, Variabilité morphologique de Botryococcus braunii (Chlorococcales, Chlorophyta): corrélations avec les conditions de croissance et la teneur en lipides, Phycologia 32 (1993) 259-265.

[33] J.J. Murray, J.B. Taylor, Phase relations and thermodynamics of refractory-metal pnictides: the arsenic decomposition pressures of Ta3As and its enthalpy of formation, J. Chem. Thermodyn. 9 (1977) 465-471.

[34] H. Takache, G. Christophe, J.F. Cornet, J. Pruvost, Experimental and theoretical assessment of maximum productivities for the microalgae chlamydomonas reinhardtii in two different geometries of photobioreactors, Biotechnol. Progr. 26 (2009) 431-440

[35] S. Meier, S.A. Mjos, H. Joensen, O. Grahl-Nielsen, Validation of a one-step extraction/methylation method for determination of fatty acids and cholesterol in marine tissues, J. Chromatogr. A 1104 (2006) 291-298.

[36] B. Moutel, M. André, D. Kucma, J. Legrand, D. Grizeau, J. Pruvost, O. Gonçalves, Assessing the biofuel production potential of Botryococcus braunii strains by sensitive rapid qualitative chemotyping using chemometrically-assisted gas chromatography-mass spectrometry, Algal Res. 11 (2015) 33-42.

[37] H. Haberkorn, C. Lambert, N. Le Goïc, M. Guéguen, J. Moal, E. Palacios, P. Lassus, P. Soudant, Effects of Alexandrium minutum exposure upon physiological and hematological variables of diploid and triploid oysters, Crassostrea gigas, Aquat. Toxicol. 97 (2010) 96-108.
[38] F. Da Costa, B. Petton, C. Mingant, G. Bougaran, C. Rouxel, C. Quéré, G.H. Wikfors, P. Soudant, R. Robert, Influence of one selected Tisochrysis lutea strain rich in lipids on Crassostrea gigas larval development and biochemical composition, Aquacult. Nutr. (2015), http://dx.doi.org/10.1111/anu.12301, ISSN: 1365-2095.

[39] T. Dudognon, C. Lambert, C. Quere, M. Auffret, P. Soudant, E. Kraffe, Mitochondrial activity, hemocyte parameters and lipid composition modulation by dietary conditioning in the Pacific oyster Crassostrea gigas, J. Comp. Physiol. B IF 20 (2014) 1-15.

[40] J.C. Dittmer, R.L. Lester, A simple, specific spray for the detection of phospholipids on thin-layer chromatograms, J. Lipid Res. 5 (1964) 126-127.

[41] S. Lê, J. Josse, F. Husson, FactoMineR: an R package for multivariate analysis, J. Stat. Softw. 25 (2008) 1-18.

[42] T. Yoshimura, S. Okada, M. Honda, Culture of the hydrocarbon producing microalga Botryococcus braunii strain Showa: optimal $\mathrm{CO}_{2}$, salinity temperature, and irradiance conditions, Bioresour. Technol. 133 (2013) 232-239.

[43] G.S. Kalacheva, N.O. Zhila, T.G. Volova, Lipid and hydrocarbon compositions of a collection strain and a wild sample of the green microalga Botryococcus, Aquat. Ecol. 36 (2002) 317-331.

[44] K. Yamaguchi, H. Nakano, M. Murakami, S. Konosu, O. Nakayama, M. Kanda, A. Nakamura, H. Iwamoto, Lipid composition of a green alga, botryococcus braunii, Agric. Biol. Chem. 51 (1987) 493-498.

[45] E. Casadevall, C. Bailliez, C. Berkaloff, F. Brenckmann, C. Chirac, B. Corre, A. Couté, D. Dif, C. Largeau, P. Metzger, J. Templier, Production d'hydrocarbures renouvelables par la culture de l'algue verte Botryococcus braunii. Etude des facteurs affectant la production des hydrocarbures: Commission des Communautés européennes; 1985.

[46] H. Kim, S. Jang, S. Kim, Y. Yamaoka, D. Hong, W.-Y. Song, I. Nishida, Y. Li-Beisson, Y. Lee, The small molecule fenpropimorph rapidly converts chloroplast membrane lipids to triacylglycerols in Chlamydomonas reinhardtii, Front. Microbiol. 6 (2015) 54

[47] P. Dörmann, Galactolipids in Plant Membranes, eLS: John Wiley \& Sons Ltd., 2001.

[48] P. Dörmann, C. Benning, Galactolipids rule in seed plants, Trends Plant Sci. 7 (2002) 112-118

[49] J. Pruvost, J.F. Cornet, J. Legrand, Hydrodynamics influence on light conversion in photobioreactors: an energetically consistent analysis, Chem. Eng. Sci. 63 (2008) 3679-3694.

[50] T. Mock, B.M. Kroon, Photosynthetic energy conversion under extreme conditions-II: the significance of lipids under light limited growth in Antarctic sea ice diatoms, Phytochemistry 61 (2002) 53-60.

[51] T. Mock, B.M. Kroon, Photosynthetic energy conversion under extreme conditions-I: important role of lipids as structural modulators and energy sink under N-limited growth in Antarctic sea ice diatoms, Phytochemistry 61 (2002) 41-51.

[52] N. Chirasuwan, R. Chaiklahan, P. Kittakoop, W. Chanasattru, Ruengjitchatchawalya M, tanticharoen M, bunnag B. anti HSV-1 activity of sulphoquinovosyl diacylglycerol isolated from spirulina platensis, Sci. Asia 35 (2009) 137-141.

[53] I. Armada, N. Fau-Mazuelos, N. Mazuelos, J.L. Fau-Rios, M. Fau-Manchado, M. Manchado, J.P. Fau-Canavate, J.P. Canavate, Differences in betaine lipids and fatty acids between Pseudoisochrysis paradoxa VLP and Diacronema vlkianum VLP isolates (Haptophyta).

[54] A. Bruno, C. Rossi, G. Marcolongo, A. Di Lena, A. Venzo, C.P. Berrie, D. Corda, Selective in vivo anti-inflammatory action of the galactolipid monogalactosyldiacylglycerol, Eur. J. Pharmacol. 524 (2005) 159-168.

[55] N. Maeda, Y. Kokai, S. Ohtani, H. Sahara, Y. Kumamoto-Yonezawa, I. Kuriyama T. Hada, N. Sato, H. Yoshida, Y. Mizushina, Anti-tumor effect of orally administered spinach glycolipid fraction on implanted cancer cells, colon-26, in mice, Lipids 43 (2008) 741-748.

[56] N. Maeda, K. Matsubara, H. Yoshida, Y. Mizushina, Anti-cancer effect of spinach glycoglycerolipids as angiogenesis inhibitors based on the selective inhibition of DNA polymerase activity, Mini Rev. Med. Chem. 11 (2011) 32-38.

[57] K. Matsubara, H. Matsumoto, Y. Mizushina, M. Mori, N. Nakajima, M. Fuchigami, H. Yoshida, T. Hada, Inhibitory effect of glycolipids from spinach on in vitro and ex vivo angiogenesis, Oncol. Rep. 14 (2005) 157-160.

[58] Y. Matsumoto, H. Sahara, T. Fujita, K. Shimozawa, M. Takenouchi, T. Torigoe, S. Hanashima, T. Yamazaki, S. Takahashi, F. Sugawara, Y. Mizushina, K. Ohta, N. Takahashi, S. Gasa, K. Jimbow, K. Sakaguchi, N. Sato, An immunosuppressive effect by synthetic sulfonolipids deduced from sulfonoquinovosyl diacylglycerols of sea urchin, Transplantation 74 (2002) 261-267.

[59] Courant FaM, Arnaud and Rabin, Graziella and Antignac, Jean-Philippe and Bizec, Bruno and Giraudeau, Patrick and Tea, Illa and Akoka, Serge and Couzinet, Aurélie and Cogne, Guillaume and Grizeau, Dominique and Gonçalves, Olivier. How metabolomics can contribute to bio-processes: a proof of concept study for biomarkers discovery in the context of nitrogen-starved microalgae grown in photobioreactors. Metabolomics 2013.

[60] K. Sakamoto, M. Baba, I. Suzuki, M.M. Watanabe, Y. Shiraiwa, Optimization of light for growth, photosynthesis, and hydrocarbon production by the colonial microalga Botryococcus braunii BOT-22, Bioresour. Technol. 110 (2012) 474-479.

[61] B.A. Knights, A.C. Brown, E. Conway, B.S. Middleditch, Hydrocarbons from the green form of the freshwater alga Botryococcus braunii, Phytochemistry 9 (1970) 1317-1324. 
[62] P. Metzger, E. Casadevall, Lycopadiene, a tetraterpenoid hydrocarbon from new strains of the green alga Botryococcus braunii, Tetrahedron Lett. 28 (1987) 3931-3934.

[63] P. Metzger, E. Casadevall, A. Coute, Botryococcene distribution in strains of the green alga Botryococcus braunii, Phytochemistry 27 (1988) 1383-1388.
[64] S. Okada, M. Murakami, K. Yamaguchi, Hydrocarbon composition of newly isolated strains of the green microalga Botryococcus braunii, J. Appl. Phycol. 7 (1995) 555-559. 